\title{
Elevated Procalcitonin and Depression As Risk Factors For Postoperative Delirium In The Elderly After Cardiac Surgery - A Prospective Observational Study.
}

\author{
Anna Kupiec \\ Wroclaw Medical University: Uniwersytet Medyczny im Piastow Slaskich we Wroclawiu \\ Barbara Adamik \\ Wroclaw Medical University: Uniwersytet Medyczny im Piastow Slaskich we Wroclawiu \\ Natalia Kozera \\ Wroclaw Medical University: Uniwersytet Medyczny im Piastow Slaskich we Wroclawiu \\ Waldemar Gozdzik ( $\square$ waldemar.gozdzik@umed.wroc.pl) \\ Uniwersytet Medyczny im Piastow Slaskich we Wroclawiu https://orcid.org/0000-0001-8668-1641
}

\section{Research}

Keywords: delirium, procalcitonin, elderly, functional decline, depression, cardiac surgery

Posted Date: October 22nd, 2020

DOI: https://doi.org/10.21203/rs.3.rs-94378/v1

License: (c) (i) This work is licensed under a Creative Commons Attribution 4.0 International License. Read Full License

Version of Record: A version of this preprint was published at Journal of Clinical Medicine on November 26th, 2020. See the published version at https://doi.org/10.3390/jcm9123837. 


\section{Abstract}

Background

One of the most common complications after cardiac surgery is delirium. Determining the origin of this complication from possible pathomechanisms is difficult. The activation of an inflammatory response during surgery has been suggested as one possible mechanism of delirium. The usefulness of the inflammatory marker procalcitonin (PCT) as a predictor of delirium after cardiac surgery with cardiopulmonary bypass (CBP) has not yet been investigated.

\section{Methods}

The purpose of this study was to prospectively investigate the risk of developing postoperative delirium in a group of elderly patients using a multivariate assessment of preoperative (PCT, comorbidities, functional decline, depression) and intraoperative risk factors. 149 elderly patients were included. Delirium was assessed using the Confusion Assessment Method for the ICU.

Results

Thirty patients (20\%) developed post-operative delirium: hypoactive in $50 \%$, hyperactive in $33 \%$, mixed in $17 \%$. Preoperative PCT above the reference range $(>0.05 \mathrm{ng} / \mathrm{mL})$ was recorded more often in patients who postoperatively developed delirium than in the non-delirium group ( $50 \%$ vs. $27 \%, p=0.019$ ). After surgery, PCT was significantly higher in the delirium than the non-delirium group: ICU admission after surgery: $0.08 \mathrm{ng} / \mathrm{mL}$, IQR $0.03-0.15 \mathrm{vs.} 0.05 \mathrm{ng} / \mathrm{mL}$, IQR 0.02-0.09, p=0.011), and for consecutive days (day 1 : $0.59 \mathrm{ng} / \mathrm{mL}$, IQR $0.25-1.55$ vs. $0.25 \mathrm{ng} / \mathrm{mL}$, IQR 0.14-0.54, p=0.003; day 2: $1.21 \mathrm{ng} / \mathrm{mL}$, IQR 0.24-3.29 vs. $0.36 \mathrm{ng} / \mathrm{mL}$, IQR 0.16-0.76, $\mathrm{p}=0.006$; day 3: $0.76 \mathrm{ng} / \mathrm{mL}$, IQR 0.48-2.34 vs. $0.34 \mathrm{ng} / \mathrm{mL}$, IQR 0.14-0.66, $\mathrm{p}=0.001$ ). Patients with delirium were older (74 years, IQR $70-76$ vs. 69 years, IQR $67-74 ; p=0.038)$ and more often had functional decline ( $47 \%$ vs. $28 \%, p=0.041)$. There was no difference in comorbidities with the exception of anaemia ( $43 \%$ vs. $19 \%, p=0.006$ ). Depression was detected in $40 \%$ of patients with delirium and in $17 \%$ without delirium ( $p=0.005)$. In a multivariable logistic regression model of preoperative procalcitonin (OR=3.05; IQR 1.02-9.19), depression (OR=5.02, IQR 1.67-15.10), age (OR=1.14; IQR 1.02-1.26), functional decline (OR=0.76; IQR 0.63-0.91) along with $\mathrm{CPB}$ time (OR=1.04; IQR 1.02-1.06) were significant predictors of postoperative delirium.

\section{Conclusion}

A preoperative PCT test and assessment of functional decline and depression may help identify patients at risk for developing delirium after cardiac surgery.

\section{Background}

In recent decades we have seen a significant ageing of the population in developed countries. Over $70 \%$ of people above the age of 60 are burdened with cardiovascular disease [1]. Consequently, the number of elderly and very elderly patients undergoing cardiac surgery is increasing [2]. As the elderly are more burdened with comorbidities, this group is at high risk of perioperative complications, including death [3]. Therefore, perioperative care for elderly patients subjected to cardiac surgery becomes a big challenge for everyone - the surgeon, anaesthesiologist, and intensivist - as is taking care of the patient after surgery. One of the most common complications after on-pump cardiac surgery, with reported incidence rates ranging up to $50 \%$, is postoperative delirium, defined as fluctuating attention and awareness disturbances. Perioperative factors and the type of cardiac surgery are associated with postoperative delirium. In our previously published study, it was shown that cardiopulmonary hyperoxia episodes might be a risk factor associated with the occurrence of postoperative delirium [4]. Three subtypes of delirium have been differentiated: hypoactive, hyperactive, and mixed [5]. All of them have been associated with prolonged hospitalization, increased death rate [6], increased risk of ICU and hospital readmission [7], and possible long-term consequences such as lower quality of life or cognitive decline after the operation [8].

It is difficult to determine the origin of this complication as the pathomechanisms are little understood, and there are many potential systemic homeostasis disorders which can lead to delirium. Several hypotheses have been described, including neuroinflammation, oxidative stress, neuroendocrine dysregulation, circadian dysregulation, and a neuronal ageing hypothesis [9]. Our knowledge of perioperative delirium risk factors in heart surgery is continuously growing, but there is still much that is unknown. The activation of

Page 2/21 
an inflammatory response after surgery has been suggested as one of the possible mechanisms of delirium [9]. The use of cardiopulmonary bypass leads to the activation of a systemic inflammatory response and is associated with increased production of various inflammatory mediators during and after surgery [10][11]. An inflammatory marker, procalcitonin (PCT), may be considered a good predictor of postoperative complications early after cardiac surgery with cardiopulmonary bypass. High levels of PCT have been associated with postoperative complications such as infection [12], organ dysfunction [13], and increased mortality [14] [15]. The usefulness of procalcitonin as a predictor of postoperative delirium caused by surgery and cardiopulmonary bypass (CBP) has not yet been investigated. Therefore, we have prospectively studied the risk of developing postoperative delirium in a group of elderly patients undergoing cardiac surgery with $\mathrm{CPB}$, using a multivariate assessment of perioperative risk factors.

\section{Methods}

The study was approved by the local Bioethics Committee (permission number 219/2016), and informed consent was collected from all patients participating in the study. Inclusion criteria were: planned cardiac surgery with cardiopulmonary bypass (CBP), age 65 years old or more, and full participation of the patient in the preoperative evaluation. Exclusion criteria were: inability to get informed consent, urgent operation, off-pump surgery, diagnosis of dementia before surgery, a different protocol of anaesthesia (total venous anaesthesia), or deep hypothermia procedures.

\section{Procalcitonin measurement}

The PCT concentrations were routinely measured before surgery (baseline) and on day 0 (ICU admission after surgery), 1, 2, and 3 after surgery. All measurements were performed in the hospital laboratory (normal serum values are below $0.05 \mathrm{ng} / \mathrm{mL}$ ) by using a chemiluminescent microparticle immunoassay (ARCHITECT B.R.A.H.M.S PCT, Abbott). The limit of quantification of the test was $0.01 \mathrm{ng} / \mathrm{mL}$, and the analytical sensitivity was $0.00 \mathrm{ng} / \mathrm{mL}$.

\section{Preoperative assessment}

A preoperative assessment was performed the day before the operation by a trained anesthesiologist and included the following evaluation of the patient's ability to care for him- or herself with I.) an Activities of Daily Living scale (ADL); II.) an Instrumental Activities of Daily Living scale (IADL); an evaluation of the occurrence of cognitive decline using the III.) Mini-Mental State Examination score (MMSE); and an assessment of the occurrence of depression with an IV.) Geriatric Depression Scale (GDS-15).

I) ADL and II) IADL are both parts of a comprehensive geriatric assessment [16] and are used to assess functional decline. The ADL questionnaire consists of 6 questions assessing basic functional activities as: 1.) using the toilet, 2.) controlling urination and defecation, 3.) bathing, 4.) eating, 5.) getting out of bed, and 6.) dressing oneself [17]. The ADL scale ranges from 0 to 6 pts., with 0 being the worst and 6 pts. being the best. A score of 6 indicates the full function and a score below 6 pts. indicates compromised daily functioning. The IADL consists of 8 questions about everyday activities as the ability: 1.) to use a phone, 2.) to do shopping, 3.) to do housekeeping, 4.) to handle finances, 5.) to use a mode of transportation, 6.) to be responsible for one's own medication, 7.) to prepare meals, and 8.) to do laundry or craftwork [18]. The IADL score ranges from 8 to 24 points (1-3 pts. for each question), with 8 pts. being the worst and 24 pts. being the best. A score below 24 indicates compromised activities related to independent living,

As older populations are at risk of cognitive impairment, cognitive decline was measured with III) the Mini-Mental State Examination (MMSE), one of the most common scores used for screening. It can also be easily used by physicians who aren't psychiatrists. The MMSE assesses seven different cognitive domains: 1 ) orientation to time (range $0-5), 2$ ) orientation to place (range $0-5), 3)$ word registration (range $0-3), 4$ ) delayed recall (range $0-3), 5)$ working memory (range $0-5), 6)$ language (range $0-8$ ), and 7) visuospatial (range 0-1). The total MMSE score ranges from 0 to 30 points. A score of 27-30 indicates no cognitive impairment, 24 to 26 indicates cognitive impairment without dementia, 19 to 23 shows mild dementia, 11 to 18 moderate dementia, and less than 10 indicates severe dementia [19].

Besides, we assessed the occurrence of depression with IV) a 15-point Geriatric Depression Scale GDS-15 with 0 pts. being the best and 15 pts. being the worst. A score $\geq 5$ indicates depression with a sensitivity of $80 \%$ and specificity of $75 \%$ [20]. The GDS-15 score results were divided into two categories: no depression with GDS- $15<5$ and depression present with GDS-15 $\geq 5$. In addition, information on comorbidities was recorded. The European System for Cardiac Operative Risk Evaluation (Euroscore II) was used to 
predict the risk of death after heart surgery, as calculated by the available online Euroscore II calculator (euroscore.org). According to WHO criteria, preoperative anaemia was defined, setting the haemoglobin cut off below $12 \mathrm{~g} / \mathrm{dL}$ for females and $13 \mathrm{~g} / \mathrm{dL}$ for males [21].

\section{Anaesthesia and surgery}

The induction of anaesthesia was conducted with sufentanil, propofol and rocuronium. Sufentanil and rocuronium infusion with inhaled sevoflurane was applied to maintain the anaesthesia. After administering heparin and achieving an activated clotting time longer than 480 seconds, CBP was initiated. A hollow fiber membrane oxygenator (Medtronic Affinity, Medtronic, Inc. Minneapolis USA) with an integrated polyester arterial line filter of $40 \mathrm{~mm}$ pore size and a roller pump with a non-pulsatile flow $2.4-2.5 \mathrm{l} / \mathrm{min} / \mathrm{m}^{2}$ (Stockert S3, Sorin Group, Germany) was used in all patients. All patients were normothermic $\left(37^{\circ} \mathrm{C}\right)$. After the operation, patients were transferred to the ICU. Sedation with propofol was continued, and patients were extubated if they were hemodynamically stable, with sufficient oxygenation and without excessive bleeding. Postoperative pain was treated with Paracetamol $1 \mathrm{~g}$ every 6 hours and Oxycodone 3-4 mg every 4 hours. Procedure parameters and postoperative complications were noted, including the type of operation, aorta cross-clamping, CBP and operation time, and ICU stay and hospitalization lengths. Acute kidney injury was diagnosed according to KDIGO criteria [22].

\section{Delirium assessment}

Patients were evaluated for delirium every 12 hours, starting the morning after the operation for three subsequent days. We chose the Confusion Assessment Method for Intensive Care Unit (CAM ICU) to assess delirium. Its reported sensitivity is $83 \%$, and specificity reaches up to $100 \%$ [23]. The CAM ICU is easy to perform and can be used by non-psychiatrists, physicians, or nurses. In our study, the CAM ICU assessment was performed by anaesthesiologists trained for that purpose. The scale includes the evaluation of four features of delirium: fluctuating changes in mental status, inattention, an altered level of consciousness, and disorganized thinking.

The examination of consciousness was conducted with the Richmond Agitation-Sedation Scale (RASS). RASS is a 10-level score between -5 and +4 points, where -5 pts. indicates unarousable, 0 pts. indicates alert and calm, and +4 is combative. The CAM ICU can be used when the RASS $\geq-3$. We used the RASS scale to identify subtypes of delirium. Hypoactive delirium was diagnosed in cases with $-3 \leq$ RASS $\leq 0$ pts., and hyperactive delirium was diagnosed in patients with RASS $>0$ pts. A mixed type of POD was diagnosed in the case of a hyper- and hypoactive type switching from one to another during the day.

\section{Statistical analysis}

All analysis was performed with Statistica 13 software (StatSoft, Inc. Tulsa, USA). Continuous variables were expressed as median (interquartile range between the 25th and 75th percentiles); categorical data were expressed as numbers and percentages. The distribution was not normal based on the Shapiro-Wilk test. Therefore, statistical analysis was performed using nonparametric tests. The Mann-Whitney U test was used for comparison of the continuous variables between study groups. Categorical variables were analyzed using the chi-square test; contingency tables were used to summarize the relationship between several categorical variables. Multivariate logistic regression analysis was performed to create a model predicting the development of postoperative delirium; the results were reported as an odds ratio (OD) with $95 \%$ confidence intervals (Cl). All the tests were conducted with a $5 \%$ significance level.

\section{Results}

Study sample

534 consecutive patients who underwent cardiac surgery between January 2017 and December 2018 were screened for inclusion/exclusion criteria. Of this number, 271 patients met the inclusion criteria and were invited to the study. Finally, informed consent was obtained from 151 patients, but two patients withdrew their consent after the operation; 149 patients were included in the final analysis. The flow diagram of the study is presented in Fig. 1.

None of the patients presented signs of infection before surgery, and the WBC count was within the reference range in both groups (with postoperative delirium: 7.37, IQR 6.04-8.57 $10^{3} / \mathrm{mm}^{3}$ vs without delirium: 7.76, IQR 6.09-8.93 103/. $\mathrm{mm}^{3} ; \mathrm{p}=0.306$ ). 
Thirty patients developed postoperative delirium (20\%), and 119 patients (80\%) did not. Hypoactive delirium was the most prevalent and was diagnosed in $50 \%(15 / 30)$ of patients. Hyperactive delirium was diagnosed in $33 \%(10 / 30)$ of patients, and $17 \%$ (5/30) of patients developed a mixed type of delirium (Fig. 2). Of all delirium cases, 23 patients experienced delirium lasting less than 12 hours, four patients between 12 and 24 hours, and three patients experienced longer delirium. The majority of delirium (19 incidences) occurred on the first day postoperatively. Nine incidences were recorded on the second day, and five on the third day (Fig. 2).

Risk factors for delirium

\section{Procalcitonin}

Preoperative (baseline) PCT levels above the reference range $(>0.05 \mathrm{ng} / \mathrm{mL}$ ) were found in $50 \%$ of patients who postoperatively developed delirium and in only $27 \%$ in the non-delirium group $(\mathrm{p}=0.019)$. The median preoperative value was $0.05 \mathrm{ng} / \mathrm{mL}(\mathrm{IQR}$ $0.01-0.08)$ in the delirium group and $0.03 \mathrm{ng} / \mathrm{mL}($ IQR $0.01-0.06)$ in the non-delirium group $(p=0.207)$. The preoperative PCT value was a strong predictor of postoperative delirium development with an odds ratio of 3.05 , as confirmed by the multivariate logistic regression model described in the section below.

After surgery, PCT levels were significantly higher in the delirium group than in patients without delirium on admission to the ICU (day $0: 0.08 \mathrm{ng} / \mathrm{mL}$, IQR $0.03-0.15$ vs. $0.05 \mathrm{ng} / \mathrm{mL}$, IQR $0.02-0.09, \mathrm{p}=0.011$ ) and for the consecutive days (day $1: 0.59 \mathrm{ng} / \mathrm{mL}$, IQR $0.25-1.55$ vs. $0.25 \mathrm{ng} / \mathrm{mL}$, IQR $0.14-0.54, \mathrm{p}=0.003$; day 2: $1.21 \mathrm{ng} / \mathrm{mL}$, IQR $0.24-3.29$ vs. $0.36 \mathrm{ng} / \mathrm{mL}$, IQR 0.16-0.76, $\mathrm{p}=0.006$; day 3: $0.76 \mathrm{ng} / \mathrm{mL}$, IQR $0.48-2.34 \mathrm{vs.} 0.34 \mathrm{ng} / \mathrm{mL}$, IQR $0.14-0.66, \mathrm{p}=0.001$, respectively, in the delirium and non-delirium group), with a peak value on the second day after surgery (Fig. 3).

\section{Age}

The median age in the group of patients with postoperative delirium was higher than in the non-delirium group (74 years, IQR 70-76 vs 69 years, IQR 67-74; $p=0.038$ ) (Table 1).

\section{Comorbidities}

The distribution of comorbidities such as cerebrovascular disease, hypertension, atrial fibrillation, diabetes, or renal insufficiency was comparable in the study groups, and anaemia was more than two times more common in the group of patients who experienced postoperative delirium compared to the group without delirium ( $43 \%$ vs $19 \%, p=0.006)$ (Table 1$)$.

\section{Euroscore II}

As estimated by the pre-surgery Euroscore II risk model, the risk of death after cardiac surgery was higher in patients who eventually developed delirium postoperatively than in the non-delirious group ( $2.5 \%$ vs $1.8 \%, p=0.009)$. The observed mortality was $3.3 \%$ in the group with delirium and $0.8 \%$ in the non-delirium group $(p=0.32)$.

\section{Table 1.}

Preoperative characteristics: an analysis comparing characteristics of subjects who developed delirium and those who did not. 


\begin{tabular}{|llll|}
\hline & Delirium & Non-delirium & P \\
\hline Preoperative characteristics & $\mathbf{N}=30$ & $\mathbf{N}=119$ & \\
\hline Age & $73,5(70-76)$ & $69(67-74)$ & 0.038 \\
\hline Gender, men, N (\%) & $18(60)$ & $79(66)$ & 0.511 \\
\hline BMI, (kg/m $\left.{ }^{2}\right)$ & $28,4(24,2-29,4)$ & $27,5(25,3-31,0)$ & 0.597 \\
\hline Euroscore II, (\%) & $2,5(1,6-5,7)$ & $1,8(1,2-2,8)$ & 0.009 \\
\hline Comorbidities, N (\%) & & & \\
\hline Cerebrovascular disease & $7(23)$ & $13(10)$ & 0.138 \\
\hline Arterial hypertension & $26(86)$ & $107(89)$ & 0.607 \\
\hline Diabetes mellitus & $11(36)$ & $44(36)$ & 0.975 \\
\hline Continuous atrial fibrillation & $2(6)$ & $11(9)$ & 0.654 \\
\hline Chronic renal insufficiency & $8(26)$ & $20(16)$ & 0.216 \\
\hline Anaemia & $13(43)$ & $23(19)$ & 0.006 \\
\hline Ejection fraction, N (\%) & $60(50-65)$ & $60(50-65)$ & 0.471 \\
\hline Nicotine abuse, N (\%) & $6(20)$ & $26(21,85)$ & 0.825 \\
\hline Data are presented as median (interquartile range) or percentage. BSA: Body Surface Area; \\
\hline
\end{tabular}

BMI: Body Mass Index;

\section{Preoperative geriatric assessment scores}

\section{MMSE}

the overall scores were not different among patients with or without postoperative delirium (median 25 pts. in each group). An analysis of the MMSE domains between patient groups revealed only a statistically significant difference for the orientation to place domain ( $p=0.02$ ); results in other domains (orientation to time, word recall, working memory, language, and visuospatial) were similar in both study groups. The majority of patients did not show signs of dementia (80\%, 24/30 in the delirium group; $71 \%$, $85 / 119$ in the non-delirium group); mild or moderate dementia was diagnosed in $20 \%$ of patients $(6 / 30)$ in the delirious group and in $29 \%(34 / 119)$ in the non-delirium group $(p=0.09)$.

ADL

the majority of patients did not show signs of a decline in functional status (93\%, 28/30 in the delirium group; $99 \%, 118 / 119$ in the non-delirium group). Compromised daily functioning was detected in 2 patients in the delirious group (both cases with 2 pts.) and in 1 in the non-delirium group (5 pts.).

\section{IADL}

no sign of decline in functional status was recorded in only $53 \%$ of patients $(16 / 30)$ in the delirium group and $72 \%(86 / 119)$ in the non-delirium group. Compromised daily functioning was detected in $47 \%$ of patients (14/30) in the delirium group and $28 \%$ $(33 / 119)$ in the non-delirium group $(p=0.046)$. Among those with compromised daily functioning, patients with postoperative delirium were less independent in terms of shopping $(p=0.041)$, housekeeping $(p<0.001)$, using a mode of transportation $(p=$ $0.014)$, being responsible for one's own medication $(p=0.035)$, preparing meals $(p=0.022)$, and doing laundry $(0.001)$ compared to the non-delirium group. 
depression was detected in 12 patients in the delirious group (40\%) and in 20 in the non-delirious group (17\%) $(p=0.005)$. The median value of GDS-15 was 5 pts. (IQR $3-7)$ in the delirious group and 3 pts. (IQR $2-5)$ in patients without delirium $(p=0.003)$.

An analysis comparing the preoperative geriatric characteristics of subjects who developed delirium and those who did not is presented in Table 2.

\section{Table 2}

Preoperative geriatric assessment: an analysis comparing the assessment of subjects who developed delirium and those who did not.

\begin{tabular}{|c|c|c|c|}
\hline & Delirium & Non-delirium & $\mathbf{P}$ \\
\hline & $N=30$ & $N=119$ & \\
\hline \multicolumn{4}{|l|}{ MMSE, N (\%) } \\
\hline no cognitive impairment (27-30 pts.) & $8(27)$ & $50(42)$ & 0.094 \\
\hline cognitive impairment, no dementia (24-26 pts.) & $16(53)$ & $35(29)$ & \\
\hline mild dementia (19-23 pts.) & $5(17)$ & $31(26)$ & \\
\hline moderate dementia (11-18 pts.) & $1(3)$ & $3(3)$ & \\
\hline severe dementia (0-10 pts.) & 0 & 0 & \\
\hline \multicolumn{4}{|l|}{ ADL, N (\%) } \\
\hline full functioning (6 pts.), N (\%) & $28(93)$ & $118(99)$ & 0.103 \\
\hline compromised functioning (< 6 pts.), N (\%) & $2(7)$ & $1(1)$ & \\
\hline \multicolumn{4}{|l|}{ IADL, N (\%) } \\
\hline full functioning (24 pts) & $16(53)$ & $86(72)$ & 0.046 \\
\hline compromised functioning (total score < 24 pts.) & $14(43)$ & $33(28)$ & \\
\hline \multicolumn{4}{|l|}{ compromised daily activities: } \\
\hline 1.) use phone & $2(7)$ & $3(3)$ & 0.471 \\
\hline 2.) shopping & $5(16)$ & $6(5)$ & 0.041 \\
\hline 3.) housekeeping & $9(30)$ & $4(4)$ & $<0.001$ \\
\hline 4.) handle finances & $7(23)$ & $23(19)$ & 0.235 \\
\hline 5.) a mode of transportation & $10(33)$ & $15(12)$ & 0.014 \\
\hline 6.) responsibility for own medication & $5(16)$ & $5(5)$ & 0.035 \\
\hline 7.) preparation of food & $5(16)$ & $4(3)$ & 0.022 \\
\hline 8.) doing laundry & $7(23)$ & $5(5)$ & 0.001 \\
\hline \multicolumn{4}{|l|}{ GDS-15, N (\%) } \\
\hline no depression (<5pts.) & $12(40)$ & $20(17)$ & 0.005 \\
\hline depression ( $\geq$ 5pts.) & $18(60)$ & $99(83)$ & \\
\hline
\end{tabular}




\section{Surgery and postoperative indices}

In the group with postoperative delirium, a complex procedure was used more often $(40 \%$ vs. $14 \%, p=0.009)$. As expected, cardiopulmonary bypass and aortic cross-clamp time were significantly longer in patients who eventually developed delirium than in the group without delirium, but anaesthesia time was similar in both study groups (Table 3 ). The postoperative analysis showed that in the group of patients with delirium, respiratory support was significantly longer than in the group without delirium (290 vs. 200 minutes, $p=0.002)$, acute kidney injury was diagnosed three times more often $(20 \% \mathrm{vs.} 7 \%, p=0.03)$, the hospital stay was longer ( 11 vs. 9 days, $p=0.002)$, and mortality was higher $(3.3 \%$ vs. $0.8 \%, p=0.323)$ (Table 3$)$.

Table 3.

Perioperative characteristics: an analysis comparing the characteristics of subjects who developed delirium and those who did not.

\begin{tabular}{|llll|}
\hline & Delirium & Non-delirium & P \\
\hline & $\mathrm{N}=30$ & $\mathrm{~N}=119$ & 0.009 \\
\hline Intra-operative characteristics & & & \\
\hline Type of operation, $\mathrm{N}(\%)$ & & $84(71)$ & $<0.001$ \\
\hline CABG & $16(53)$ & $18(15)$ & 0.004 \\
\hline Valve only & $2(7)$ & $17(14)$ & 0.101 \\
\hline CABG + valve & $12(40)$ & $79(67-94)$ & 0.002 \\
\hline CBP time (min) & $102(81-127)$ & $43(34-60)$ & 0.025 \\
\hline AoX time (min) & $57(43-81)$ & $255(235-280)$ & 0.133 \\
\hline Anaesthesia time (min) & $272(240-305)$ & & 0.002 \\
\hline Post-operative characteristics & & $200(175-270)$ & 0.323 \\
\hline Respiratory support (minutes) & $290(210-525)$ & $8(7)$ \\
\hline AKI, N (\%) & $6(20)$ & $3(2-5)$ & $9(8-11)$ \\
\hline ICU stay (days) & $3(2-6)$ & $1(0,8)$ & \\
\hline Hospital stay (days) & $11(10-15)$ & $1(3,3)$ & \\
\hline Death, N (\%) & & & \\
\hline $\begin{array}{l}\text { Data are presented as median (interquartile range) or percentage. CBP: cardiopulmonary bypass; AoX: aorta cross clamp; AKI: } \\
\text { acute kidney injury; ICU: intensive care unit }\end{array}$ & & \\
\hline
\end{tabular}

\section{Prediction model of postoperative delirium}

Multivariate logistic regression analysis was performed to create a model to predict the development of postoperative delirium. The model's backward selection determined the choice of the variables from the set of perioperative parameters. The baseline procalcitonin (OR = 3.05; IQR 1.01-9,19), depression (OR = 5.02, IQR 1.67-15.10), age (OR = 1.14; IQR 1.02-1.26), IADL score (OR = $0.76 ; 0.63-0.91)$, and $C P B$ time $(O R=1.04 ;$ IQR 1.02-1.06) were significant predictors of postoperative delirium; other parameters did not enter the model. The results are presented in Table 4.

Table 4

Univariate and multivariate logistic regression analysis of the predictors of delirium. 


\begin{tabular}{|c|c|c|c|c|c|c|}
\hline & \multicolumn{3}{|c|}{ Univariate analysis } & \multicolumn{3}{|c|}{ Multivariate analysis } \\
\hline & Odds Ratio & $95 \% \mathrm{Cl}$ & $\mathbf{p}$ & Odds Ratio & $95 \% \mathrm{Cl}$ & p \\
\hline РCT baseline & 2,70 & $1.15-6.32$ & 0.022 & 3.05 & $1.01-9.19$ & 0.048 \\
\hline IADL & 0.81 & $0.70-0.92$ & 0.002 & 0.76 & $0.63-0.91$ & 0.003 \\
\hline Depression & 3.30 & $1.37-7.91$ & 0.008 & 5.02 & $1.67-15.10$ & 0.004 \\
\hline Age & 1.08 & $1.01-1.17$ & 0.031 & 1.14 & $1.02-1.26$ & 0.016 \\
\hline CPB time & 1.02 & $1.01-1.04$ & $<0.001$ & 1.04 & $1.02-1.06$ & $<0.001$ \\
\hline AoX time & 1.02 & $1.01-1.04$ & 0.003 & & & \\
\hline Euroscore & 1.21 & $1.06-1.37$ & 0.004 & & & \\
\hline Gender & 0.75 & $0.33-1.73$ & 0.511 & & & \\
\hline MMSE & 0.96 & $0.84-1.09$ & 0.595 & & & \\
\hline ADL & 0.34 & $0.10-1.16$ & 0.086 & & & \\
\hline Anaemia before surgery & 3.19 & $1.35-7.49$ & 0.007 & & & \\
\hline
\end{tabular}

\section{Discussion}

The key finding of this study is that elevated preoperative procalcitonin, along with other preoperative factors such as age, depression, and compromised daily functioning, accompanied by prolonged CBP time, are the most critical factors in the development of postoperative delirium after cardiac surgery. To our knowledge, this is the first study showing the usefulness of procalcitonin as a predictor of the development of postoperative delirium in patients undergoing cardiac surgery.

In the present study, it was observed that patients who experienced postoperative delirium had higher procalcitonin levels both before surgery and on the following days, compared to patients without delirium. PCT is a peptide precursor of calcitonin and a biomarker of inflammation. In ICU patients, PCT has been used to identify bacterial infections and monitor antibiotic therapy as part of standard care for septic patients. Procalcitonin levels may arise in the course of the inflammatory reaction in response to surgical trauma without infection, and a transient increase in the PCT level has been observed even during uncomplicated heart surgery [24]. In cardiac surgery, the systemic inflammatory response can be activated by many factors such as surgical trauma, CBP circuit, endotoxemia, and ischemia-reperfusion injury. Various inflammatory mediators, including PCT, are released and lead to systemic effects such as vasodilatation and disturbances in the microcirculation [10]. Long CBP is a powerful inductor of a systemic inflammatory reaction, and brain function may also be affected. Consistent with the neuroinflammatory hypothesis of postoperative delirium, inflammatory mediators released when the systemic inflammatory response has been activated cross the blood-brain barrier, activating microglial cells to produce inflammatory mediators. Consequently, damage to brain tissue, dysfunction of neuron activity, disturbances in the neurotransmitter system, impaired synaptic conduction, and leaking of intercellular connections of blood-brain barrier cells were detected [9] [25].

Here, we assessed PCT because daily PCT measurements are readily available as part of routine in-hospital monitoring, and the predictive value of PCT for diagnosing complications after cardiac surgery had been previously confirmed. Clementi et al. presented results that the PCT measurement performed 48 hours after the cardiac operation was a good predictor of postoperative renal and respiratory complications [14]. In another study, Klingele et al. showed that a single PCT measurement taken the day after surgery was a predictor of delayed complications such as prolonged hospitalization, ICU readmission, and hospital death [26].

The importance of procalcitonin as a predictor of delirium has not yet been established. Earlier, McGrane et al. demonstrated that in a population of non-cardiac ICU patients, high PCT values recorded on ICU admission predicted prolonged periods of acute brain dysfunction, linking inflammation as an essential mechanism in the pathophysiology of delirium [27]. In a later prospective study 
by Nemeth et al., the relationship between changes in the procalcitonin concentration measured on the first day after surgery and the occurrence of postoperative cognitive dysfunction was assessed in a population of elderly patients undergoing on-pump cardiac surgery, and no relationship was found between inflammatory response and cognitive dysfunction [28]. In this study, according to the multivariate logistic regression analysis, a PCT concentration above normal before surgery significantly increased the risk of postoperative delirium with an odds ratio of $3.05(p=0.048)$ in a population of patients undergoing cardiac surgery. After the operation, the median level of PCT was elevated with a peak value on the second day. This observation was expected and could be explained by the activation of a systemic inflammatory response during surgery. However, it should be emphasized that in patients with postoperative delirium, PCT was significantly higher than in patients without delirium during the entire follow-up. These observations confirm the utility of PCT measurements in predicting delirium. A PCT test is readily available (hospital laboratory, point of care testing), fast, and relatively cheap; therefore, a measurement before and after operation may be an additional indicator useful for the early identification of patients at risk for postoperative delirium.

The causes of delirium are multifactorial. According to multivariate logistic regression analysis, the best model for predicting delirium development after cardiac surgery included the preoperative PCT concentration, IADL score, the presence of depression, age, and the duration of CPB. The elderly are particularly sensitive to the development of postoperative delirium; in addition, delirium duration is longer in elderly patients than in younger patients subjected to cardiac surgery. Previously, Cereghetti et al. found that each year of life significantly increased postoperative delirium risk with an OR of 1.06 [29]. These results coincide with our research; according to the multivariate logistic regression analysis, the patient's age was a significant factor of the model that predicted postoperative delirium with an odds ratio of 1.13 .

Depression is frequent in older people and seems to be another critical risk factor of postoperative delirium. We reported here that the presence of preoperative depression was associated with a 5 -fold increased risk of postoperative delirium. A study by Eshmawe et al. confirmed that a higher preoperative depression score was associated with an increased risk of postoperative delirium [30]. In another study, Oldham et al. demonstrated a relationship between the occurrence of preoperative depression and the development and severity of delirium after CABG. The authors used three different scales to diagnose depression, and only one scale (Patient Health Questionnaire 9) was predictive of delirium, while the results of two other scores (GDS-15 and HDRS) were shown to have little or no association with postoperative delirium [31]. Different scales have been used to measure depression, and it remains unclear which measure of depression may be most predictive of outcome.

Advanced age is one of the most important risk factors for functional deterioration assessed by the IADL score. It was estimated that $40 \%$ of men and more than $50 \%$ of women were limited in at least one IADL activity [32]. A decline in physical activity such as doing housework, travel, and shopping were more age-dependent than cognitive activities such as using a telephone, managing finances, or taking one's medication [33]. In our research, patients who developed postoperative delirium had significantly compromised physical activities assessed with the IADL score. Moreover, in the multivariate logistic regression analysis, a lower IADL score estimated before surgery was a significant risk factor for postoperative delirium. These results confirm the importance of examining depression or the deterioration of physical and cognitive activity before an operation in an elderly patient. As part of a comprehensive geriatric assessment, tools such as the IADL and GDS-15 should be a routine part of managing an elderly population to help identify cases of increased risk of postoperative delirium.

Comorbidities are known risk factors for the development of postoperative delirium [34]. In our study, a majority of patients were diagnosed with arterial hypertension; diabetes and chronic renal insufficiency were common. Except for anaemia, there was no difference in the distribution of comorbidities between groups. Anaemia was diagnosed in $43 \%$ of patients in the group who developed postoperative delirium, and only $19 \%$ in the group without delirium. Previous studies have shown that preoperative anaemia was considered a risk factor for the outcome in non-cardiac surgery; it was associated with a more extended hospital stay, a higher risk of perioperative complications, and higher mortality [35]. In a recent study of 800 patients undergoing elective noncardiac surgery, anaemia was associated with postoperative delirium and longer hospitalization [36]. The impact of preoperative anaemia on postoperative delirium in the cardiosurgical population is not yet well understood, and the results published so far have often been contradictory. In a systematic review based on 34 studies, several studies identified anaemia as an important risk factor for delirium following on-pump cardiac surgery, while others did not find an association [37]. In a recently published study by Smulter et al, the preoperative haemoglobin level was not associated with postoperative delirium [38]. In our study, preoperative anaemia was more than twice as common in the group with postoperative delirium than in patients without delirium (43 vs $19 \%$, $p$

Page $10 / 21$ 
= 0.006); however, in a multivariate logistic regression analysis, the presence of preoperative anaemia was not included in the

prediction model. It seems that this issue requires further evaluation in larger populations.

In the present study, more patients who postoperatively developed delirium required a complex procedure. This resulted in a significant prolongation of CBP time. Along with long aortic cross-clamping, prolonged CBP time has been one of the most important factors of postoperative delirium [6]. This observation was also confirmed in our study in the multivariate logistic regression analysis. The duration of $\mathrm{CPB}$ was a significant factor in the model predicting postoperative delirium with an odds ratio of 1.04. This observation leads to the conclusion that qualifying elderly patients for long and complex procedures require careful consideration and balancing the risks and potential benefits.

Our study has several limitations. First, we didn't assess the long term consequences of delirium, postoperative cognitive decline, or a reduced quality of life after the operation. Second, our model was based on patients in one centre. Multi-centred research on the assessment of procalcitonin and other inflammatory markers is worth considering.

\section{Conclusions}

Preoperative factors such as procalcitonin above a normal range, older age, a diagnosis of depression, impaired functional status, along with the intraoperative factor of a longer cardiopulmonary bypass time are associated with an increased risk of developing postoperative delirium. Thus, a preoperative PCT test and assessment with an IADL and GDS-15 score may help identify patients at risk of developing postoperative delirium after cardiac surgery.

\section{Abbreviations}

PCT

Procalcitonin

CBP

Cardiopulmonary Bypass

IQR

Interquartile Range

$\mathrm{OR}$

Odds Ratio

ICU

Intensive Care Unit

ADL

Activities of Daily Living

IADL

Instrumental Activities of Daily Living

MMSE

Mini Mental State Examination score

GDS-15

15 - Item Geriatric Depression Scale

WHO

World Health Organisation

KDIGO

the Kidney Disease Improving Global Outcomes

CAM ICU

Confusion Assessment Method for Intensive Care Unit

RASS

Richmond Agitation-Sedation Scale

\section{Declarations}




\section{ETHICS APPROVAL AND CONSENT TO PARTICIPATE}

The study was approved by the Bioethics Committee of Wroclaw Medical University (permission number 219/2016). Informed consent was collected from all patients participating in the study.

\section{Consent For Publications}

Not applicable

\section{AVAILABILITY OF DATA AND MATERIALS}

The datasets used and/or analyzed during the current study are available from the corresponding author on reasonable request.

\section{COMPETING INTERESTS}

The authors declare that they have no competing interests.

\section{FUNDING}

The authors acknowledge funding support from Wroclaw Medical University, Poland (grant No. ST.A170.18.024).

\section{AUTHORS' CONTRIBUTIONS}

AK: collected and interpreted the patient's data and was a contributor in writing

BA: interpreted the patient's data and was a contributor in writing

NK: collected patients data

WG: interpreted the patient's data and was a contributor in writing

All authors read and approved the final manuscript

\section{ACKNOWLEDGEMENTS}

The authors wish to thank Lukasz Stróżecki, MSc, for performing statistical analysis of the data.

\section{References}

1. Benjamin EJ, Virani SS, Callaway CW, Chamberlain AM, Chang AR, Cheng S, et al. Heart Disease and Stroke Statistics-2017 Update. Circulation. 2017.

2. lung B, Baron G, Butchart EG, Delahaye F, Gohlke-Bärwolf C, Levang OW, et al. A prospective survey of patients with valvular heart disease in Europe: The Euro Heart Survey on valvular heart disease. Eur Heart J. 2003;24:1231-43.

3. Ranucci M, Castelvecchio S, Menicanti L, Frigiola A, Pelissero G. Risk of assessing mortality risk in elective cardiac operations: Age, creatinine, ejection fraction, and the law of parsimony. Circulation. 2009;119:3053-61.

4. Kupiec A, Adamik B, Forkasiewicz-gardynik K, Goździk W. Aging-12-103058. 2020;12:7006-14.

5. Lin Y, Chen J, Wang Z. Meta-analysis of factors which influence delirium following cardiac surgery. J Card Surg. 2012;27:48192.

6. Bakker RC, Osse RJ, Tulen JHM, Kappetein AP, Bogers AJJC. Preoperative and operative predictors of delirium after cardiac surgery in elderly patients. Eur J Cardio-thoracic Surg. 2012;41:544-9.

7. Koster S, Hensens AG, Schuurmans MJ, Van Der Palen J. Consequences of delirium after cardiac operations. Ann Thorac Surg [Internet]. Elsevier Inc.; 2012;93:705-11. Available from: http://dx.doi.org/10.1016/j.athoracsur.2011.07.006.

8. Sauër AC, Veldhuijzen DS, Ottens TH, Slooter AJC, Kalkman CJ, Van Dijk D. Association between delirium and cognitive change after cardiac surgery. Br J Anaesth. 2017;119:308-15. 
9. Maldonado JR. Delirium pathophysiology: An updated hypothesis of the etiology of acute brain failure. Int J Geriatr Psychiatry. 2018;33:1428-57.

10. Paparella D, Yau TM, Young E. Cardiopulmonary bypass induced inflammation: Pathophysiology and treatment. An update. Eur J Cardio-thoracic Surg. 2002;21:232-44.

11. Gozdzik W, Adamik B, Gozdzik A, Rachwalik M, Kustrzycki W, Kübler A. Unchanged plasma levels of the soluble urokinase plasminogen activator receptor in elective coronary artery bypass graft surgery patients and cardiopulmonary bypass use. PLoS One. 2014;9.

12. Li Q, Zheng S, Zhou PY, Xiao Z, Wang R, Li J. The diagnostic accuracy of procalcitonin in infectious patients after cardiac surgery: a systematic review and meta-analysis. J Cardiovasc Med (Hagerstown) [Internet]. 2020; Available from: https://doi.org/10.2459/JCM.0000000000001017.

13. Brocca A, Virzì GM, de Cal M, Giavarina D, Carta M, Ronco C. Elevated Levels of Procalcitonin and Interleukin-6 are Linked with Postoperative Complications in Cardiac Surgery. Scand J Surg. 2017;106:318-24.

14. Clementi A, Virzì GM, Muciño-Bermejo MJ, Nalesso F, Giavarina D, Carta M, et al. Presepsin and Procalcitonin Levels as Markers of Adverse Postoperative Complications and Mortality in Cardiac Surgery Patients. Blood Purif. 2019;47:140-8.

15. Clementi A, Brocca A, Virzì GM, De Cal M, Giavarina D, Carta M, et al. Procalcitonin and Interleukin-6 Levels: Are They Useful Biomarkers in Cardiac Surgery Patients? Blood Purif. 2017;43:290-7.

16. Partridge JSL, Harari D, Martin FC, Dhesi JK. The impact of preoperative comprehensive geriatric assessment on postoperative outcomes in older patients undergoing scheduled surgery: A systematic review. Anaesthesia. 2014;69:8-16.

17. Katz S. Assessing self-maintenance: Activities of daily living, mobility, and instrumental activities of daily living. J Am Geriatr Soc. 1983;31:721-7.

18. Vittengl JR, White CN, McGovern RJ, Morton BJ. Comparative validity of seven scoring systems for the instrumental activities of daily living scale in rural elders. Aging Ment Heal. 2006;10:40-7.

19. Foley T, McKinlay A, Warren N, Stolwyk RJ. Assessing the sensitivity and specificity of cognitive screening measures for people with Parkinson's disease. NeuroRehabilitation. 2019;43:491-500.

20. Wancata J, Alexandrowicz R, Marquart B, Weiss M, Friedrich F. The criterion validity of the geriatric depression scale: A systematic review. Acta Psychiatr Scand. 2006;114:398-410.

21. Who CM. Haemoglobin concentrations for the diagnosis of anaemia and assessment of severity. Geneva, Switz World Heal Organ [Internet]. 2011;1-6. Available from: http://scholar.google.com/scholar?

$\mathrm{hl}=$ en\&btnG=Search\&q=intitle:Haemoglobin+concentrations+for+the+diagnosis+of+anaemia+and+assessment+of+severity\#1.

22. Kellum JA, Lameire N, Aspelin P, Barsoum RS, Burdmann EA, Goldstein SL, et al. Kidney disease: Improving global outcomes (KDIGO) acute kidney injury work group. KDIGO clinical practice guideline for acute kidney injury. Kidney Int Suppl. 2012;2:1138.

23. Chanques G, Ely EW, Garnier O, Perrigault F, Eloi A, Carr J, et al. The 2014 updated version of the Confusion Assessment Method for the Intensive Care Unit compared to the 5th version of the Diagnostic and Statistical Manual of Mental Disorders and other current methods used by intensivists. Ann Intensive Care [Internet]. Springer International Publishing; 2018;8. Available from: https://doi.org/10.1186/s13613-018-0377-7.

24. Sponholz C, Sakr Y, Reinhart K, Brunkhorst F. Diagnostic value and prognostic implications of serum procalcitonin after cardiac surgery: A systematic review of the literature. Crit Care. 2006;10.

25. Cascella M, Muzio MR, Bimonte S, Cuomo A, Jakobsson JG. Postoperative delirium and postoperative cognitive dysfunction: Updates in pathophysiology, potential translational approaches to clinical practice and further research perspectives. Minerva Anestesiol. 2018;84:246-60.

26. Klingele M, Bomberg H, Schuster S, Schäfers HJ, Groesdonk HV. Prognostic value of procalcitonin in patients after elective cardiac surgery: a prospective cohort study. Ann Intensive Care. Springer Paris; 2016;6.

27. McGrane S, Girard TD, Thompson JL, Shintani AK, Woodworth A, Ely EW, et al. Procalcitonin and C-reactive protein levels at admission as predictors of duration of acute brain dysfunction in critically ill patients. Crit Care [Internet]. BioMed Central Ltd; 2011;15:R78. Available from: http://ccforum.com/content/15/2/R78. 
28. Nemeth E, Vig K, Racz K, Koritsanszky KB, Ronkay KI, Hamvas FP, et al. Influence of the postoperative inflammatory response on cognitive decline in elderly patients undergoing on-pump cardiac surgery: A controlled, prospective observational study. BMC Anesthesiol BMC Anesthesiology. 2017;17:1-10.

29. Cereghetti C, Siegemund M, Schaedelin S, Fassl J, Seeberger MD, Eckstein FS, et al. Independent Predictors of the Duration and Overall Burden of Postoperative Delirium After Cardiac Surgery in Adults: An Observational Cohort Study. J Cardiothorac Vasc Anesth [Internet]. Elsevier Inc.; 2017;31:1966-73. Available from: http://dx.doi.org/10.1053/j.jvca.2017.03.042.

30. Eshmawey M, Arlt S, Ledschbor-Frahnert C, Guenther U, Popp J. Preoperative Depression and Plasma Cortisol Levels as Predictors of Delirium after Cardiac Surgery. Dement Geriatr Cogn Disord. 2020;48:207-14.

31. Oldham MA, Hawkins K, Lin I, Deng Y, Hao Q, Scoutt LM, et al. HHS Public Access. 2020;27:476-86.

32. Scheel-Hincke LL, Möller S, Lindahl-Jacobsen R, Jeune B, Ahrenfeldt LJ. Cross-national comparison of sex differences in ADL and IADL in Europe: findings from SHARE. Eur J Ageing [Internet]. Springer Netherlands; 2020;17:69-79. Available from: https://doi.org/10.1007/s10433-019-00524-y.

33. Bleijenberg N, Zuithoff NPA, Smith AK, de Wit NJ, Schuurmans MJ. Disability in the individual ADL, IADL, and mobility among older adults: A prospective cohort study. J Nutr Heal Aging. 2017;21:897-903.

34. Guenther U, Theuerkauf N, Frommann I, Brimmers K, Malik R, Stori S, et al. Predisposing and precipitating factors of delirium after cardiac surgery: A prospective observational cohort study. Ann Surg. 2013;257:1160-7.

35. Fowler AJ, Ahmad T, Abbott TEF, Torrance HD, Wouters PF, De Hert S, et al. Association of preoperative anaemia with postoperative morbidity and mortality: an observational cohort study in low-, middle-, and high-income countries. $\mathrm{Br} \mathrm{J} A n a e s t h$ [Internet]. Elsevier Ltd; 2018;121:1227-35. Available from: https://doi.org/10.1016/j.bja.2018.08.026.

36. Kunz JV, Spies CD, Bichmann A, Sieg M, Mueller A. Postoperative anaemia might be a risk factor for postoperative delirium and prolonged hospital stay: A secondary analysis of a prospective cohort study. PLoS One. 2020;15:1-12.

37. Gosselt ANC, Slooter AJC, Boere PRQ, Zaal IJ. Risk factors for delirium after on-pump cardiac surgery: A systematic review. Crit Care [Internet]. Critical Care; 2015;19:1-8. Available from: http://dx.doi.org/10.1186/s13054-015-1060-0.

38. Smulter N, Engström KG, Appelblad M, Gustafson Y, Lingehall HC, Svenmarker S, et al. Disturbances in Oxygen Balance During Cardiopulmonary Bypass: A Risk Factor for Postoperative Delirium. J Cardiothorac Vasc Anesth [Internet]. Elsevier Inc.; 2017;32:684-90. Available from: http://dx.doi.org/10.1053/j.jvca.2017.08.035.

\section{Figures}




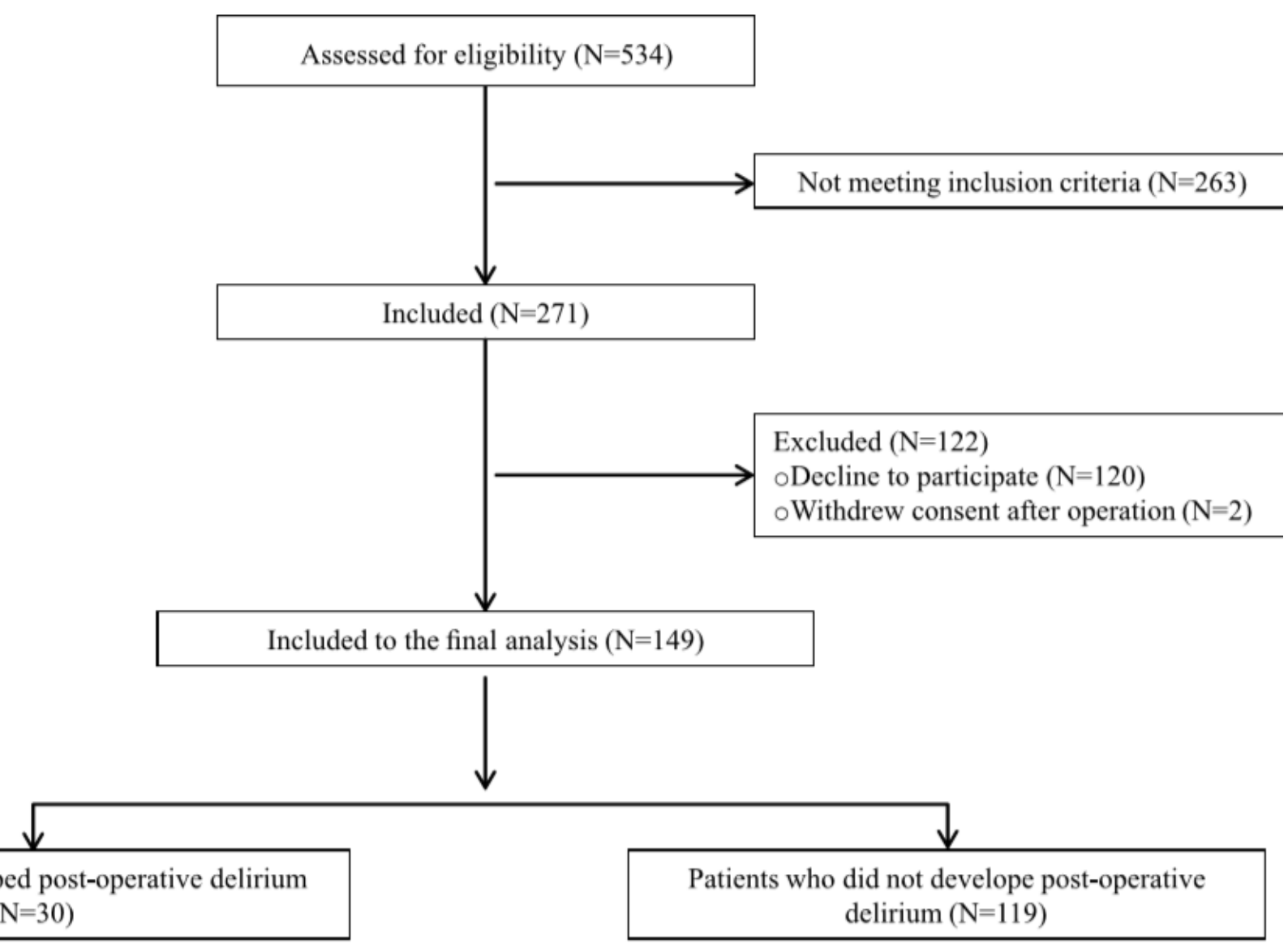

\section{Figure 1}

Flow diagram of the study

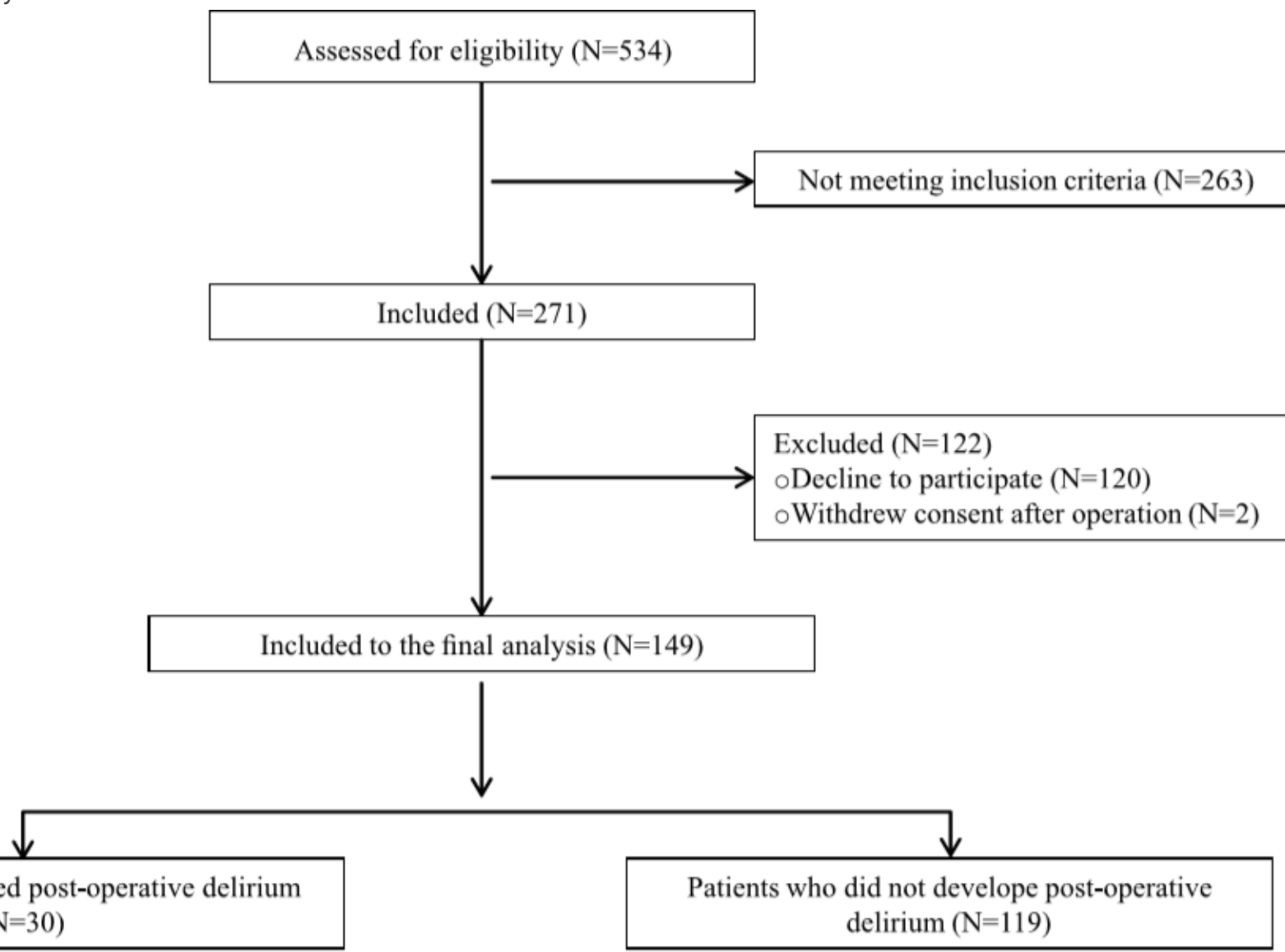




\section{Figure 1}

Flow diagram of the study

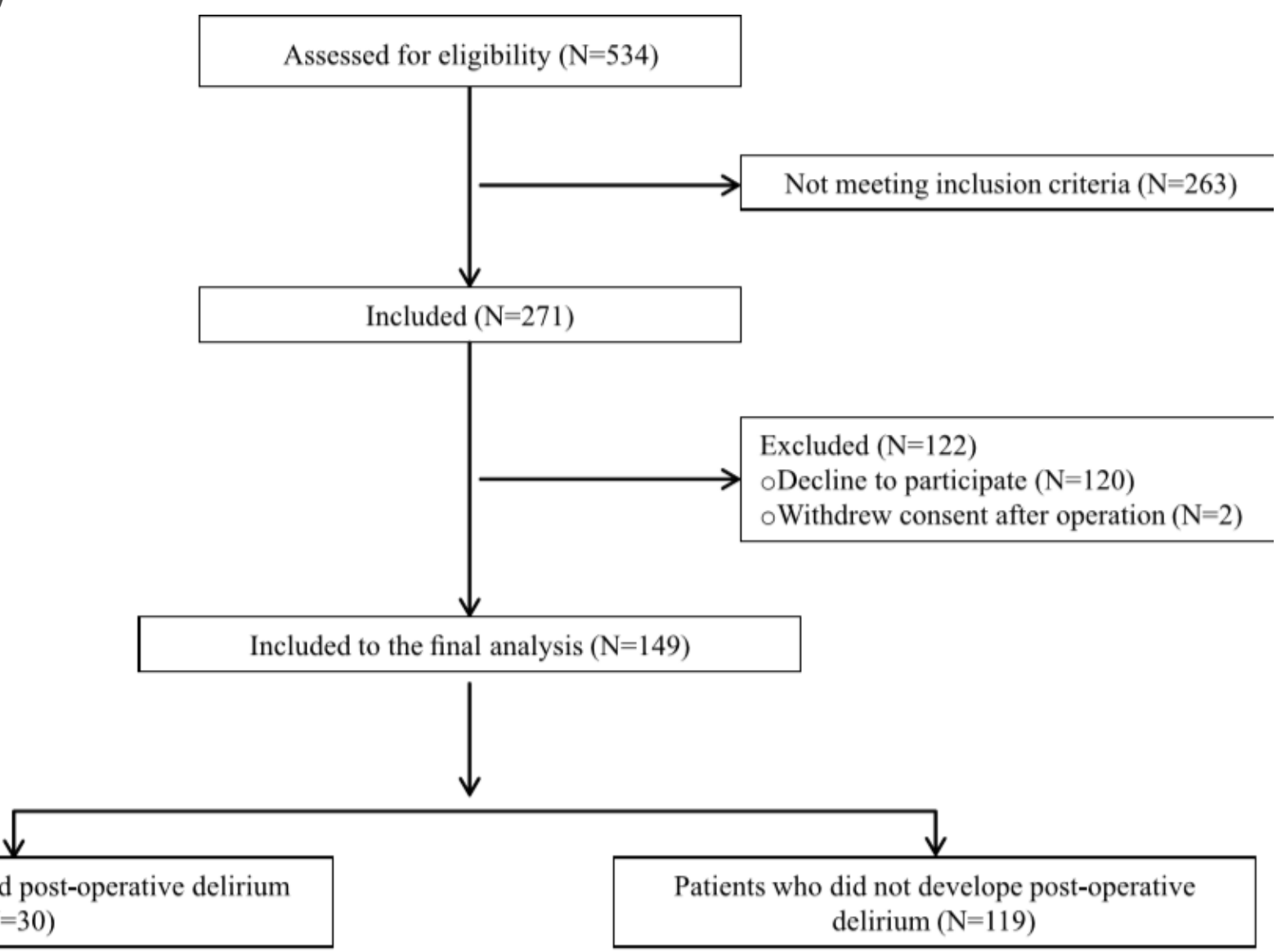

\section{Figure 1}

Flow diagram of the study 


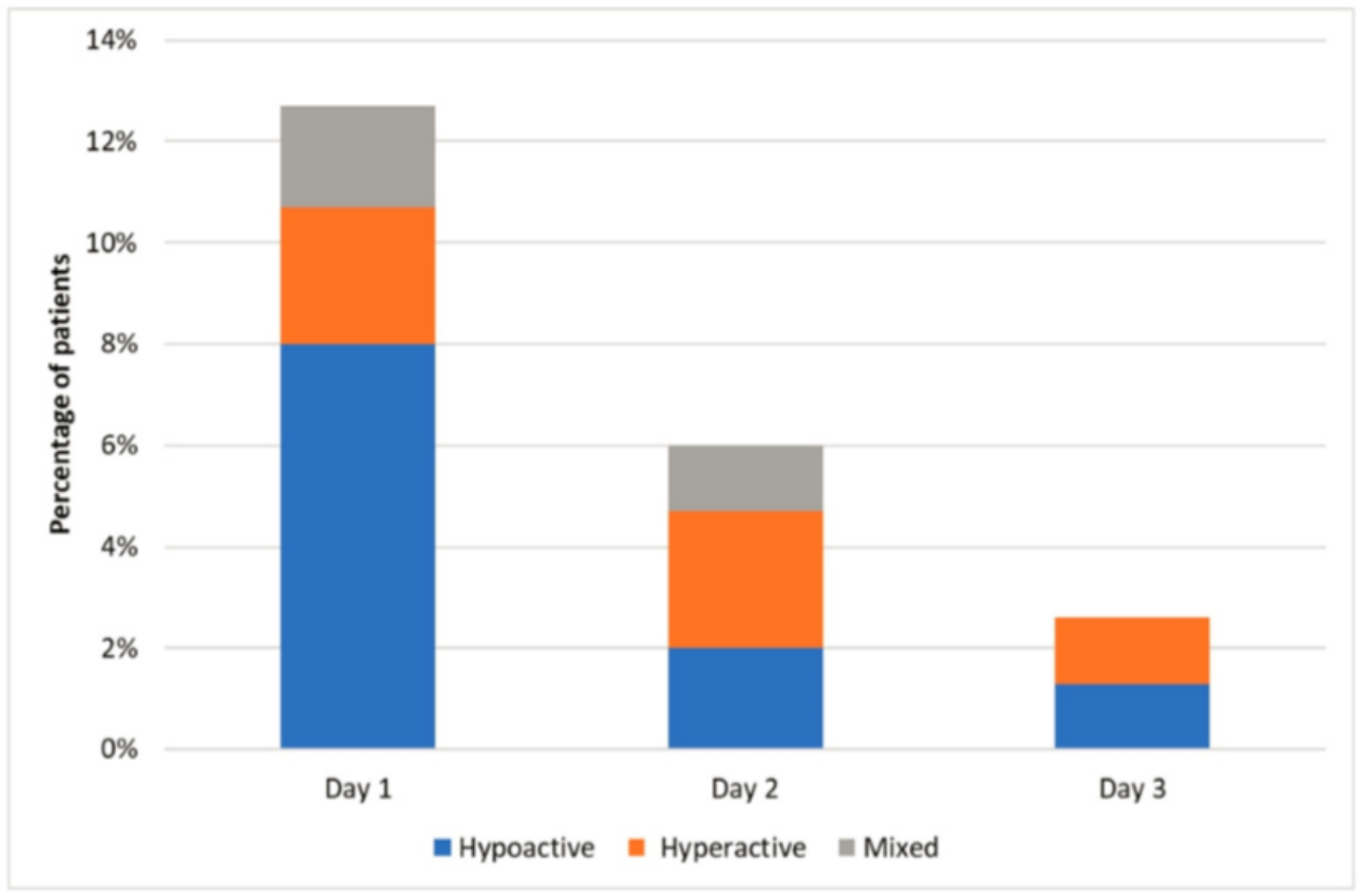

Figure 2

Postoperative delirium cases identified on day 1, 2, and 3 after surgery. 


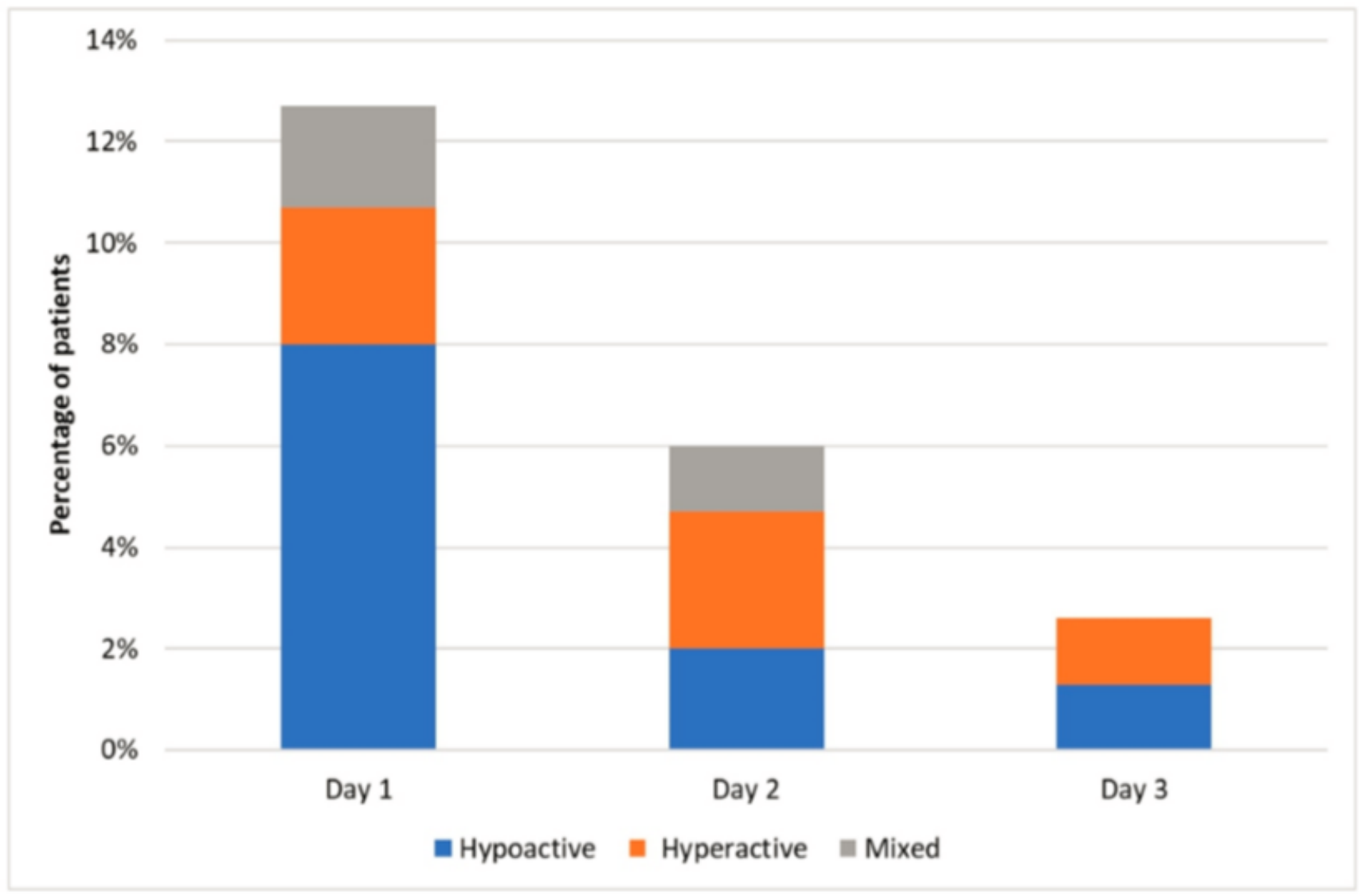

Figure 2

Postoperative delirium cases identified on day 1, 2, and 3 after surgery. 


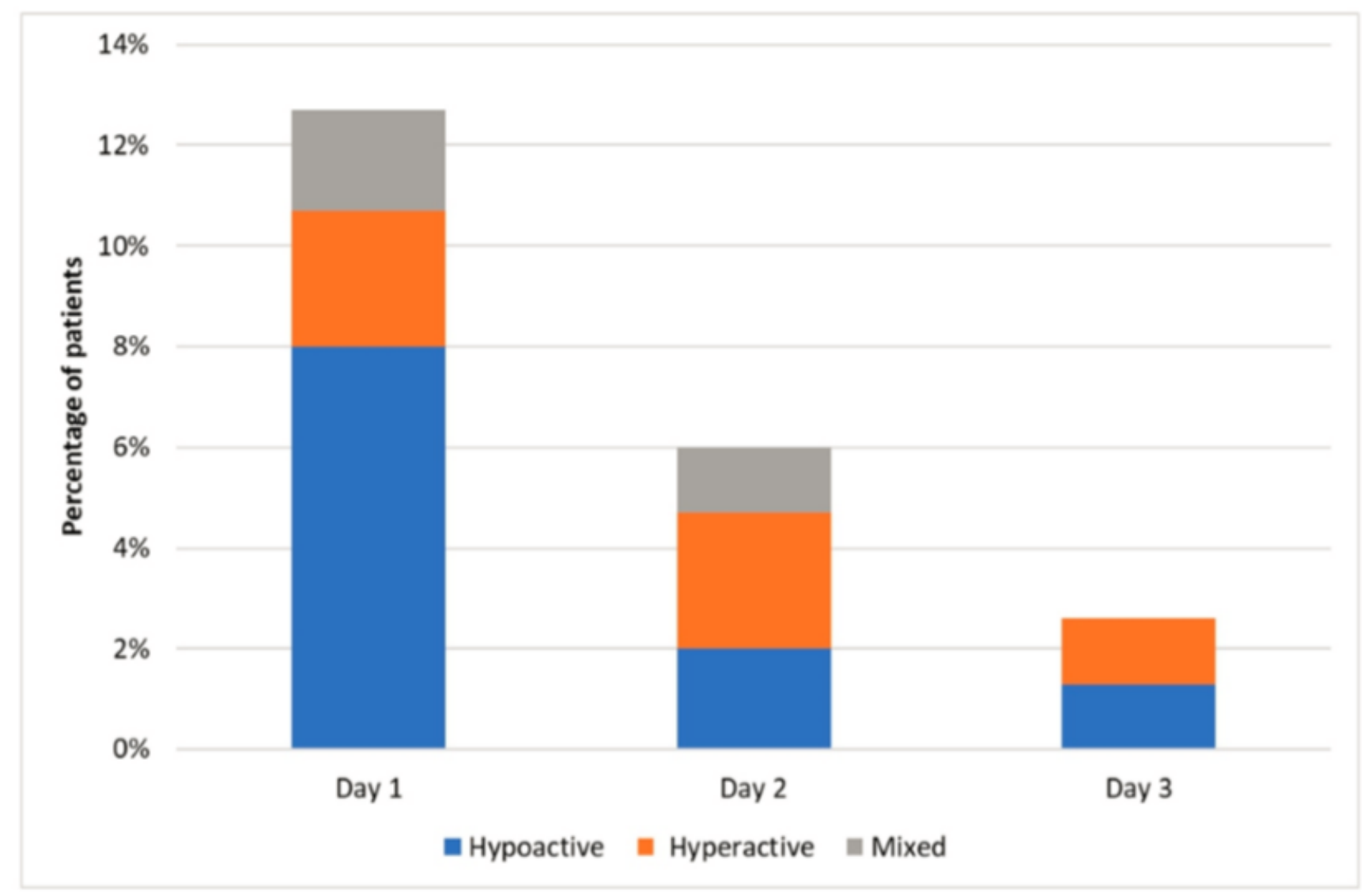

Figure 2

Postoperative delirium cases identified on day 1,2 , and 3 after surgery.

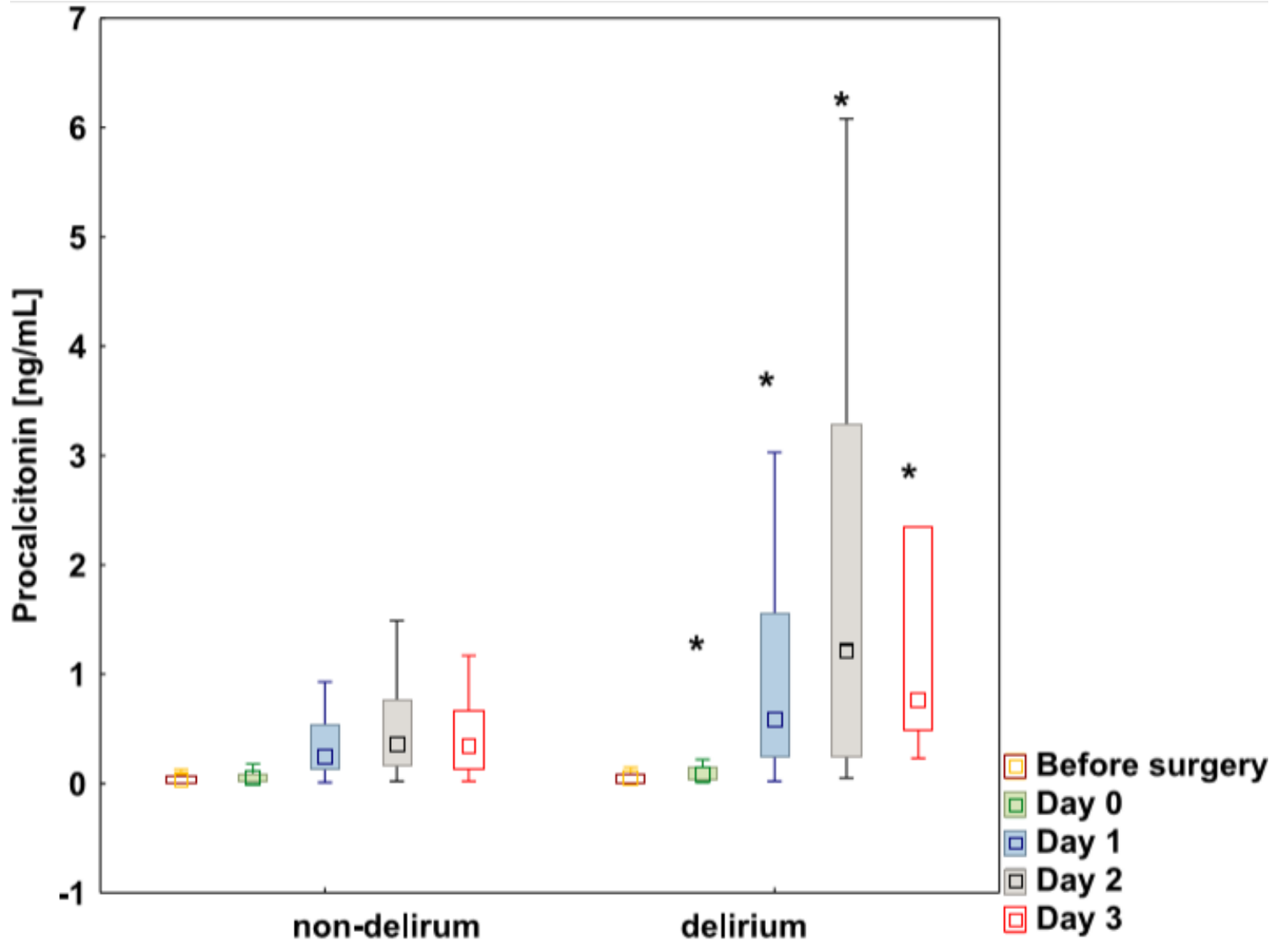

Page $19 / 21$ 
Figure 3

Procalcitonin concentrations in patients with and without postoperative delirium measured before surgery (baseline) and on consecutive days after the surgery. *statistically significant differences between groups; boxplot showing minimum and maximum (whiskers), median (middle point), and IQR values (box)

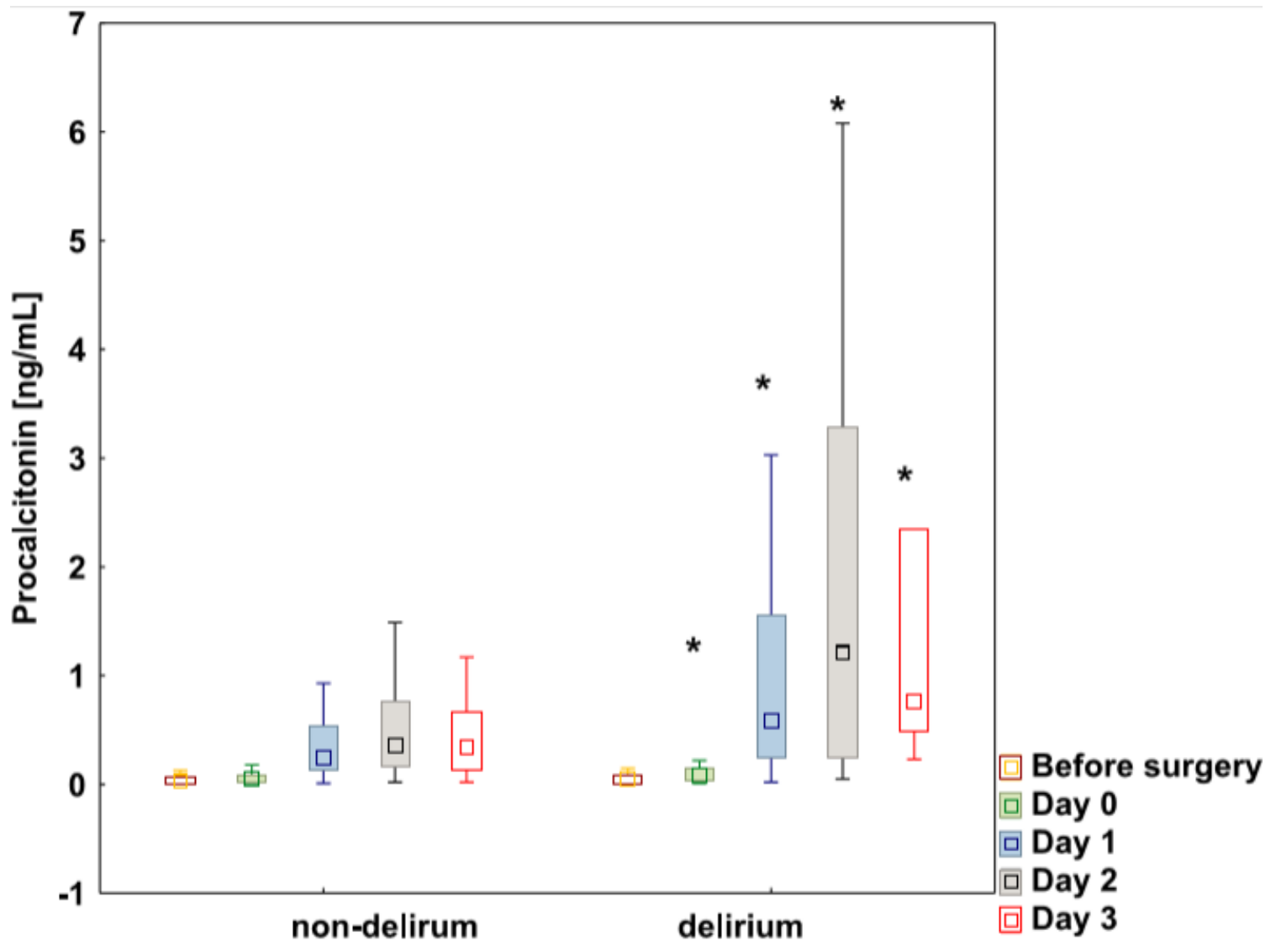

Figure 3

Procalcitonin concentrations in patients with and without postoperative delirium measured before surgery (baseline) and on consecutive days after the surgery. *statistically significant differences between groups; boxplot showing minimum and maximum (whiskers), median (middle point), and IQR values (box) 


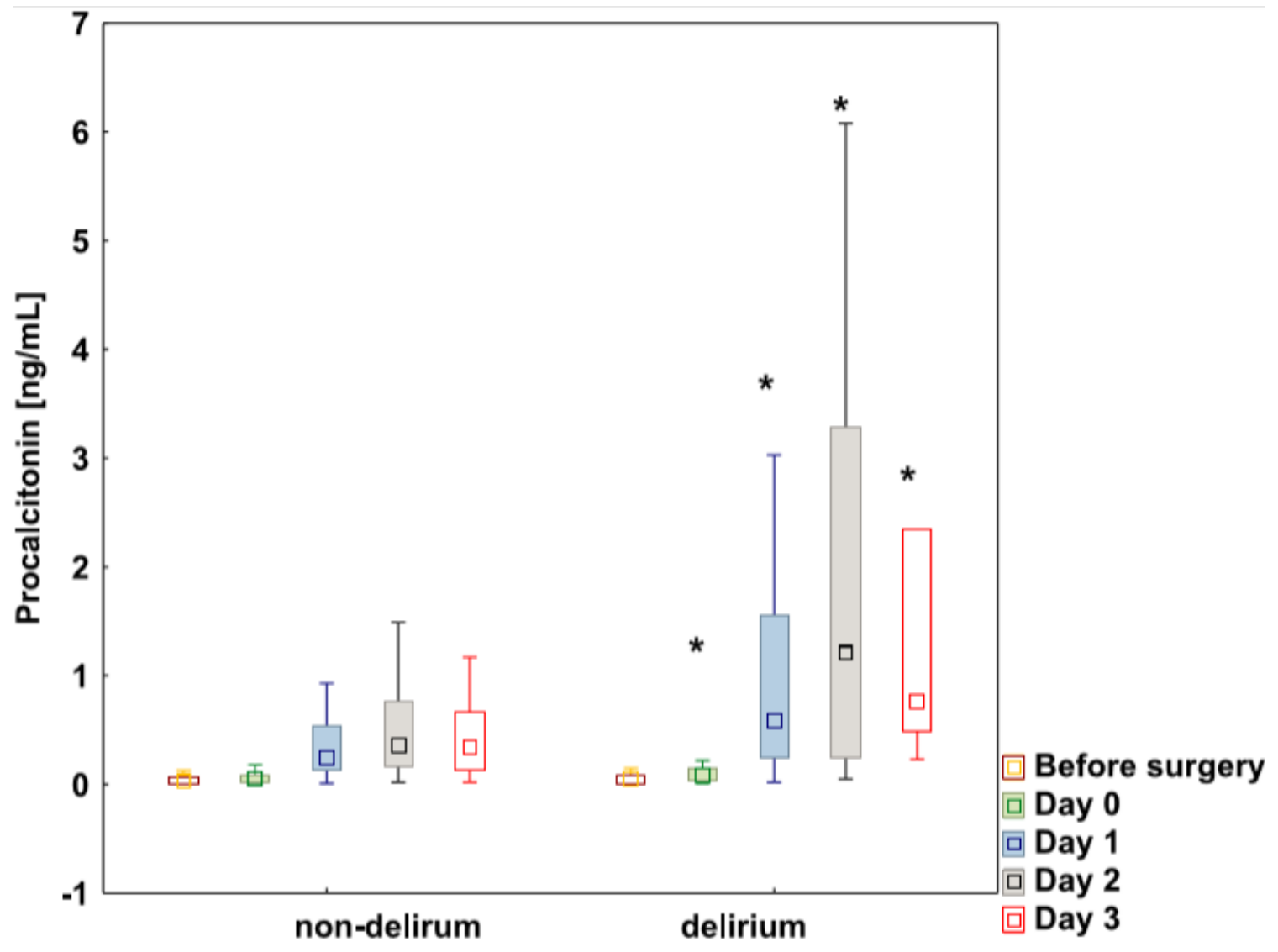

Figure 3

Procalcitonin concentrations in patients with and without postoperative delirium measured before surgery (baseline) and on consecutive days after the surgery. *statistically significant differences between groups; boxplot showing minimum and maximum (whiskers), median (middle point), and IQR values (box)

\section{Supplementary Files}

This is a list of supplementary files associated with this preprint. Click to download.

- graphicalabstract.jpg

- graphicalabstract.jpg

- graphicalabstract.jpg 